\title{
Is the Four-Day School Week Detrimental to Student Success?
}

\author{
Timothy W. Tharp ${ }^{1}$, John Matt ${ }^{2}$, Frances L. O'Reilly ${ }^{2}$ \\ ${ }^{1}$ Superintendent, Sunburst School District, USA \\ ${ }^{2}$ Associate Professor, Department of Educational Leadership, University of Montana, USA \\ Correspondence: John Matt, Associate Professor, Department of Educational Leadership, University of Montana, USA
}

Received: December 1, 2015 Accepted: December 11, $2015 \quad$ Online Published: January 16, 2016

doi:10.11114/jets.v4i3.1308 URL: http://dx.doi.org/10.11114/jets.v4i3.1308

\begin{abstract}
School districts across the United States are implementing four-day school weeks. This study looks at the relationship between student achievement in the four-day school week compared to student achievement in the five-day school week. This analysis focused on a common criteria referenced test given to all students over a period of seven years in a single western state. The study provided conclusive evidence that students in the four-day week did not performed as well, over time, when compared to students in the traditional five-day week settings.
\end{abstract}

Keywords: achievement, four-day week, school calendar

\section{Introduction}

Many public schools, particularly rural schools, have modified their schedule so students and teachers attend school only four days each week. The four-day school week, over seven years, has been responsible for serious declines in student achievement as measured by criterion referenced testing in one western state. Anecdotes exist from school districts that report positive results in student achievement, absenteeism, and general satisfaction with the four-day week. There are also studies specific to individual school districts in the United States regarding the four-day school week, but there are no conclusive studies on the impact of the four-day school week on student achievement over time. This study identified serious declines in achievement in rural schools in a western state where the four-day school week has become a trend.

The traditional school year in America's public schools is approximately 180 days, which typically follows an agrarian calendar. Many in the educational field believe that the conventional school year met the needs of the $19^{\text {th }}$ century farmer (Davis \& Farbman, 2004; Gold, 2002; National Education Commission on Time and Learning, 1994). Other literature stated the school calendar in America allowed students to vacate the urban areas during the heat of the summer (Gold, 2002). Whatever the initial causes were, the calendar in the American education system has been fairly consistent across all 50 states (Gold, 2002). Despite recent pushes by educational groups to add more hours to the school day and/or add days to the school year, this traditional format of a five-day week for 180 days is not likely to change (Chen, 2007).

Ever-increasing monetary pressures have forced schools to consider alternative approaches to scheduling with the intent to reduce costs. A recent study compiled by the American Association of School Administrators found that nearly one in seven school districts considered a four-day school week as a way to combat budget short-falls (Vogt, 2008). However, there is a body of research that indicated the projected savings in the move to a four-day week is not significant (Sagness \& Salzman, 1993; Webster, 2013).

Intuition would tell us that a $20 \%$ savings should be realized in certain areas of a school district budget by shifting calendars to a four-day week from a five-day week. In this scenario, custodial, food-service, and transportation line-items should see immediate savings. Depending on building usage, there should also be savings in heating costs and possibly secretarial time. However, these costs totaled together are still a small percentage of the overall budget, because the largest part of a school budget is the salary and benefits of the professional teaching staff (AASA, 2010).

\section{Methodology}

The research question that this study explored was: What is the difference between student achievement scores in schools that utilize a four-day school week as compared to student scores in schools that follow a traditional five-day 
schedule? The participants in this causal comparative study consisted of every student in the western state who took the criterion referenced test between 2007 and 2013. The number of students that took this criterion referenced test state-wide was over 70,000 annually. The number of these students who attended a four-day week school started at 207 in 2007 and increased annually to 2685 in 2013.

\section{Data Collection}

Data were requested and provided by the State Education Agency (SEA) regarding student achievement from 2007-2013. The spreadsheet provided by the SEA contained data from the criterion referenced test from a census of every school in the state. Data provided indicated the number of students tested along with the percentages of students that were novice, nearing proficiency, proficient, and advanced in reading, mathematics, and science.

\section{Data Analysis}

The data collected in the study were analyzed to determine whether differences exist between the groups of students in schools with a four-day week as compared to those in a traditional five-day week. The No Child Left Behind Act (NCLB), in part, determines if a school has made Adequate Yearly Progress (AYP) by calculating the percentage of students who are determined to be proficient or advanced on this criterion referenced test.

\section{Results}

From this study it is clear that the four-day school week had a negative impact on student achievement in reading and mathematics as measured by the criterion referenced test. Figure 1 and Figure 2 summarized the results and graphically demonstrated how the five-day week students performed better over time in reading and math than the students in the four-day school week.

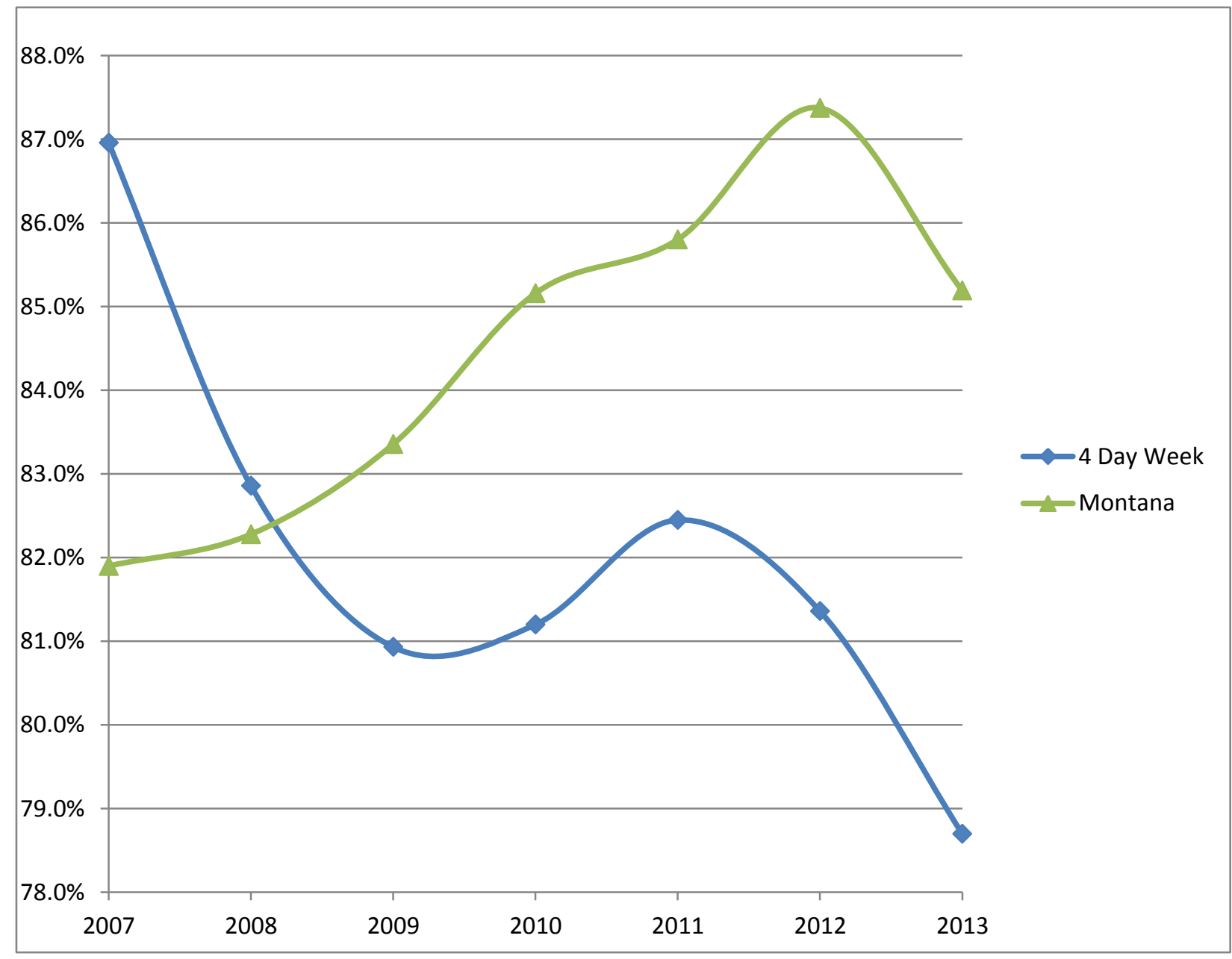

Figure 1. Comparison of reading scores for four-day week students v. five-day week students $2007-2013$.

When all students in schools with a five-day week were compared to students in four-day week schools over a period of 6 years, reading outcomes fell dramatically from $87 \%$ to below $79 \%$. Statewide averages rose from approximately $82 \%$ to just above $85 \%$ proficient and advanced on the same criterion referenced test. 
Figure 2 summarized the results and graphically demonstrated how the four-day-a-week students did not perform as well, over time, in mathematics compared to the total population of students tested. Over a six year period, mathematics test scores for students in four-day-a-week schools dropped from $70.5 \%$ to $57.2 \%$ for proficient and advanced. However, in the five-day-a-week schools students' scores rose from $64.2 \%$ to $67.3 \%$ proficient and advanced as measured by the criterion referenced test.

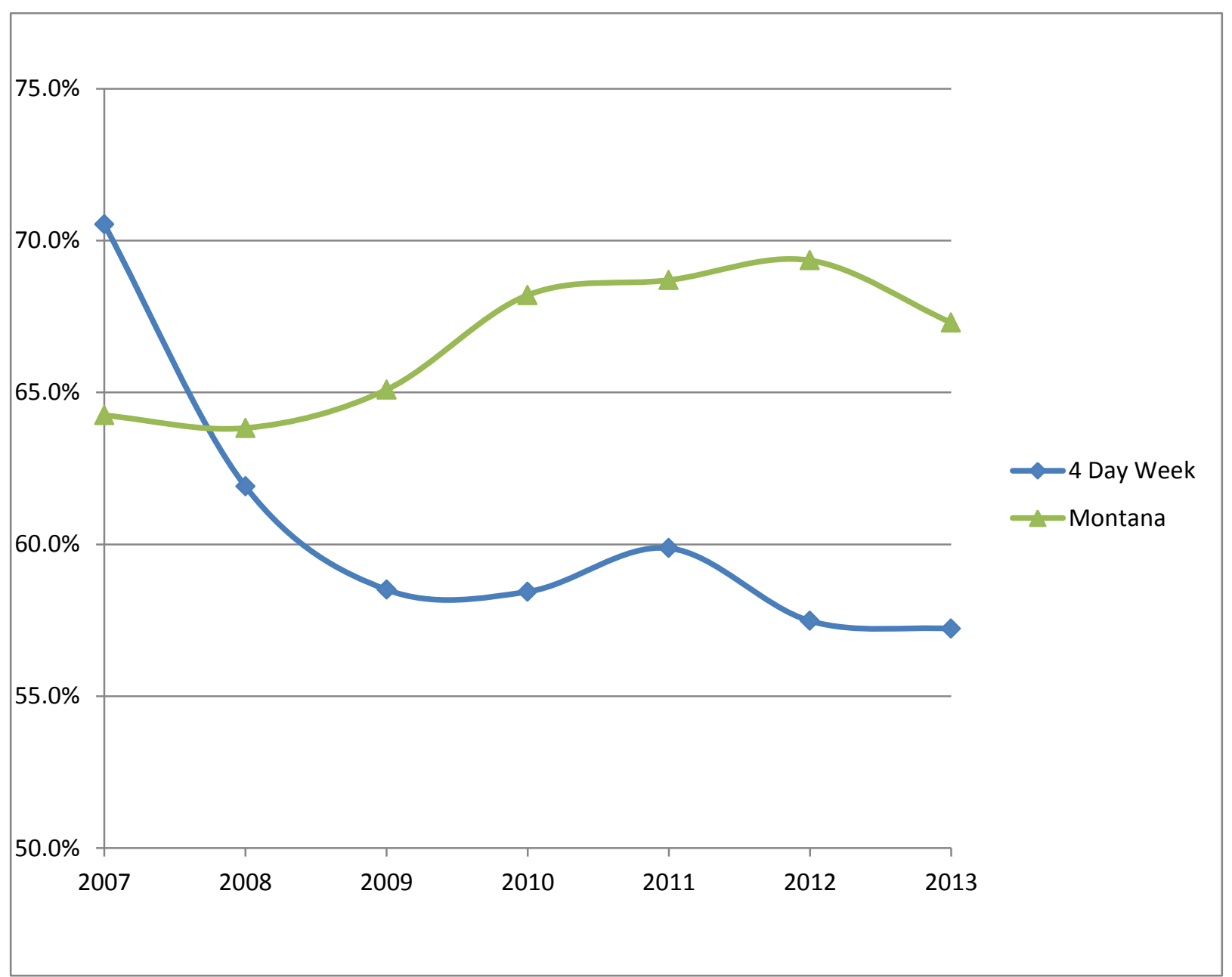

Figure 2. Comparison of mathematics scores for four-day week students v. five-day week students 2007 - 2013.

As schools made the transition away from the five-day week, additional students became part of the four-day week group. The researcher sorted the data to identify those students who were in a four-day week setting for five or more years. The achievement data for the four-day week students were compared to students in the five-day week. Figure 3 and Figure 4 show the comparison between the two groups in reading and mathematics respectively. 


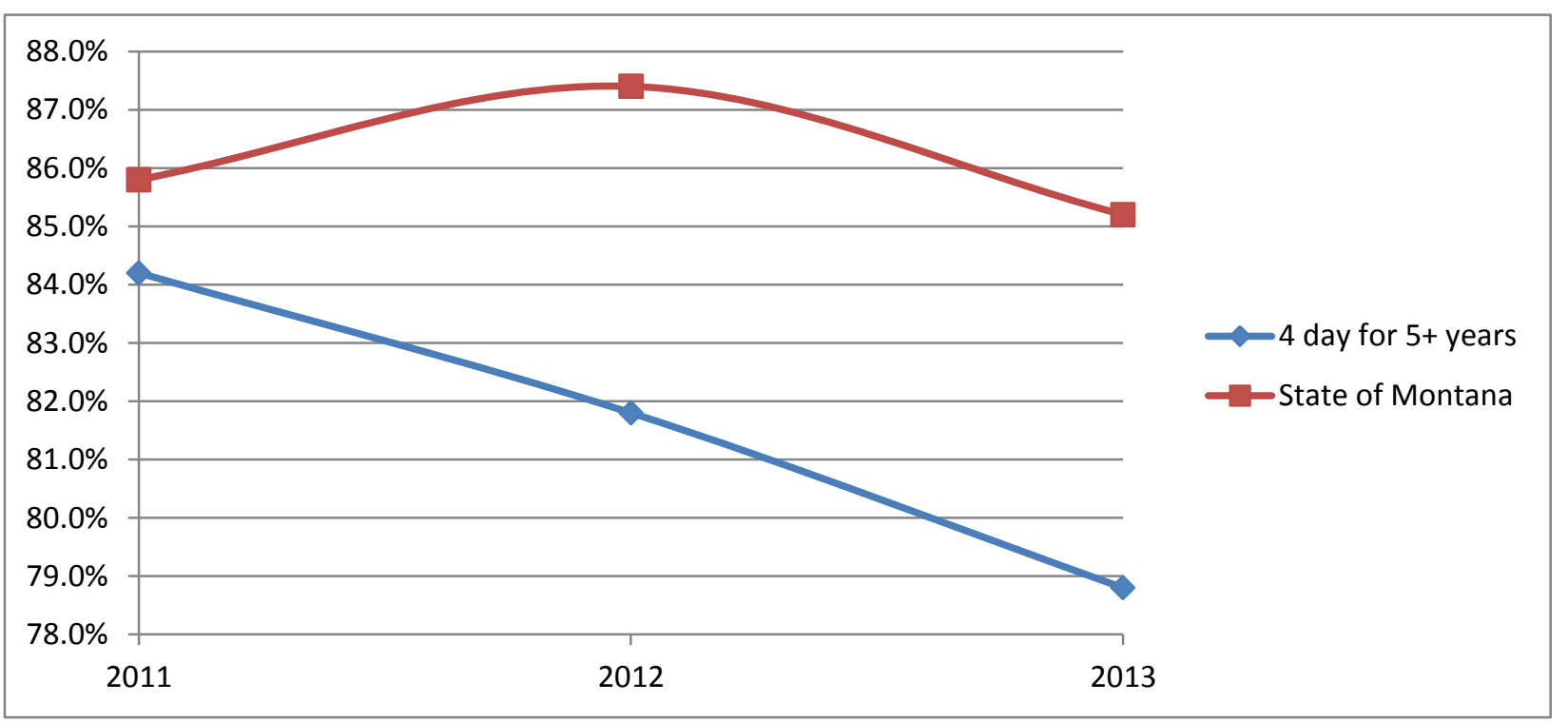

Figure 3. Percentage of students proficient and advanced in reading in schools operating with a four-day week for over five years as compared to five-day week totals.

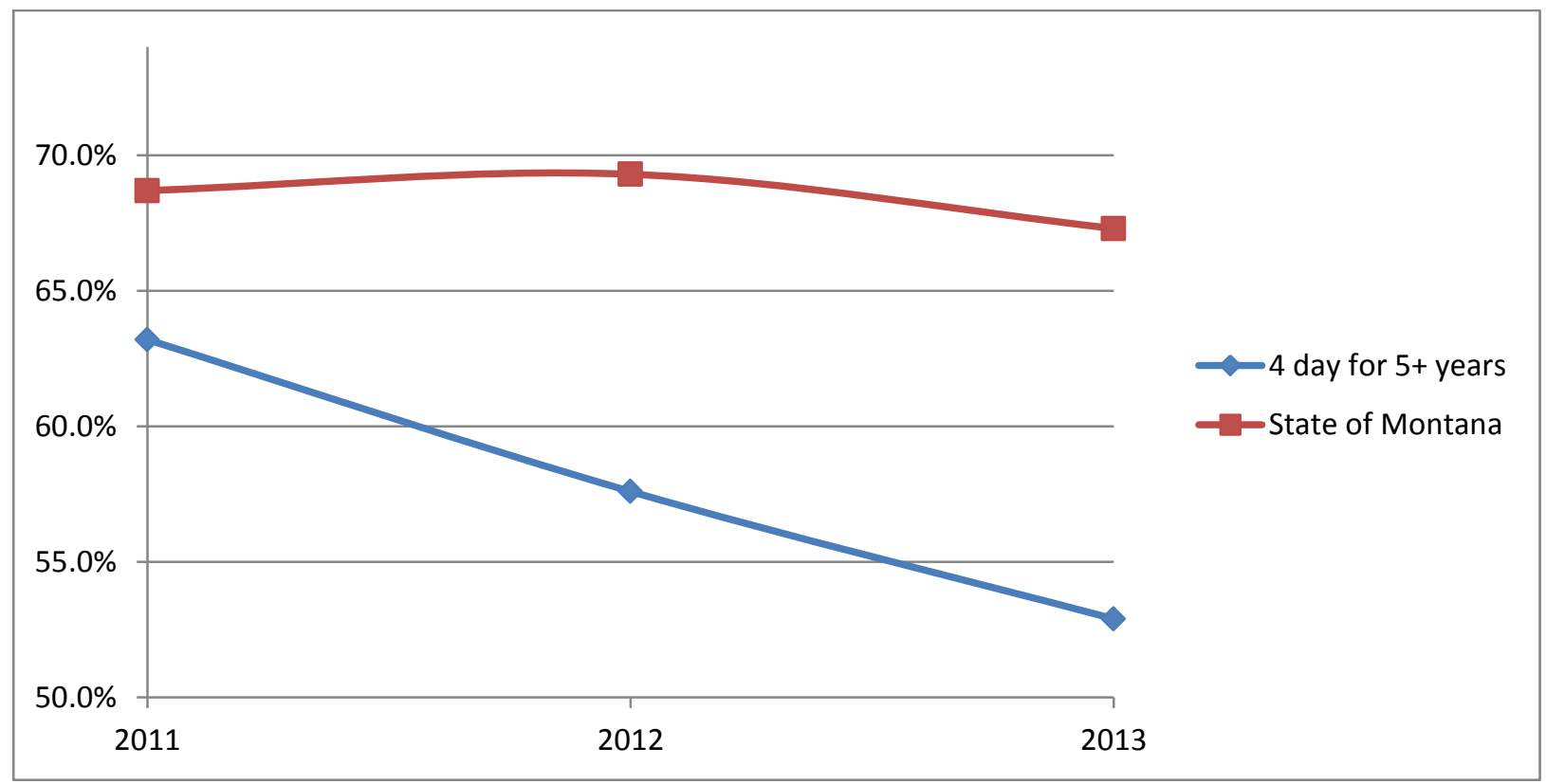

Figure 4. Percentage of students proficient and advanced in mathematics in schools operating with a four day week for over five years as compared to five-day week totals.

To further delineate the testing results for students in the four-day-a-week schools, Figures 5 and 6 demonstrate student achievement in reading and mathematics by cohort group based on the year they began the four-day-a-week school year. 


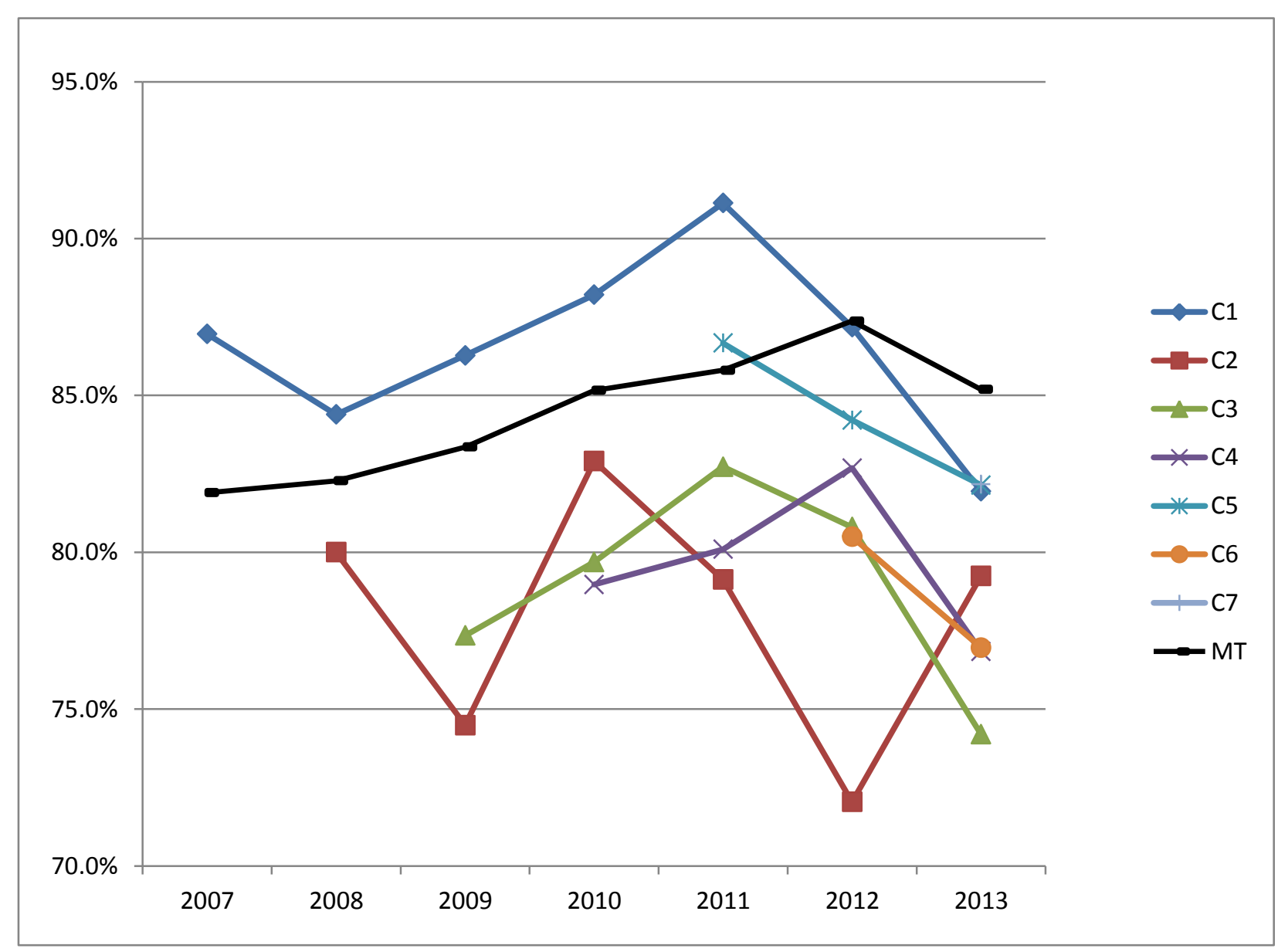

Figure 5. Reading scores of cohort groups. 


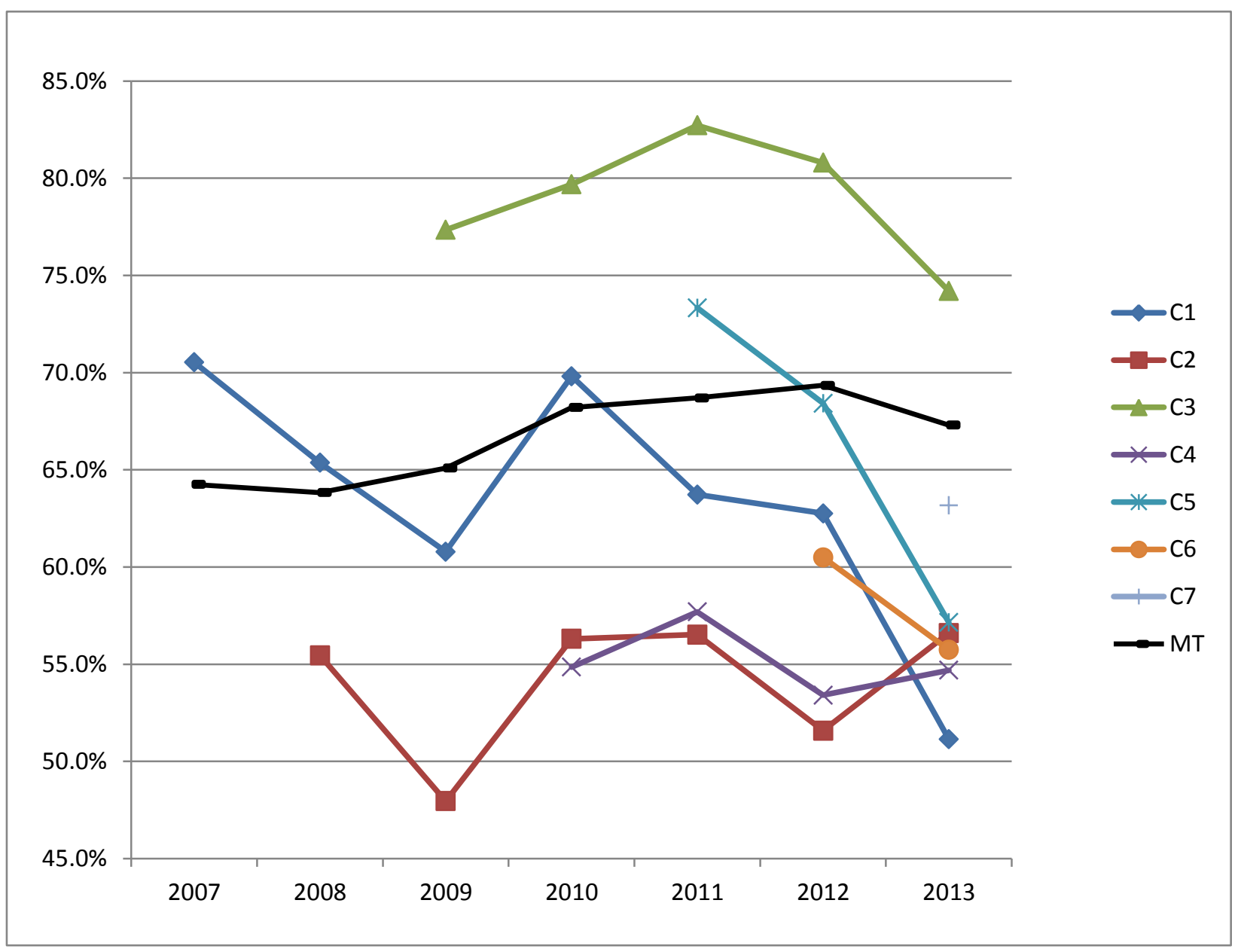

Figure 6. Mathematics scores of cohort groups.

\section{Conclusions}

While the reasons for making the change to a four-day school week vary from district to district, one constant is that schools that convert to a four-day week typically do not change back to a traditional five-day per week format as it becomes part of the culture of the district. Parents, teachers, administrators, and patrons of schools that convert to a four-day week are concerned about student academic performance. The concern focuses on the loss of approximately $20 \%$ of the days of instruction, even though the instructional hours are theoretically included in the other four days. In the first two years of implementation student scores in four- day week schools are better than the rest of the state. However, once the four-day week becomes part of the culture, the loss of the days of instruction appears to negatively affect student performance.

If a school district is seriously considering converting to the four-day school week, a comprehensive plan must be in place to address the long-term loss of instructional days. This plan should include professional development for all personnel to include pedagogical strategies for teaching in a four-day week. In addition, a strategy must be in place to monitor student performance to ensure adequate student achievement over time.

\section{References}

American Association of School Administrators (AASA), (2010, May 24), School Budgets 101, Retrieved from http://www.aasa.org/uploadedFiles/Policy_and_Advocacy/files/SchoolBudgetBriefFINAL.pdf on October 11, 2013

Chen, M. (2007). Afterschool Advantage Powerful New Learning Opportunities. Moorestown, NJ: Foundations, Inc. Retrieved from http://www.nccap.net/media/pages/Afterschool_Advantage.pdf

Davis, J., \& Farbman, D. (2004). Rethinking Time: The Next Frontier of Education Reform. Education Week.

Gold, K.M. (2002). School's in: The History of Summer Education in American Public Schools. P. Lang.

National Education Commission on Time and Learning (April 1994), Prisoners of Time. 
Sagness, R. L., \& Salzman, S. A. (1993). Evaluation of the Four day School Week in Idaho Suburban Schools. Paper presented at the Annual Meeting of the Northern Rocky Mountain Educational Research Association (Jackson, WY, October 1-2, 1993).

Vogt, A. (2008). American Association of School Administrators. AASA Survey Finds Rising Fuel, Energy Costs Stressing School Budgets. Retrieved November 27, 2008, from http://www.aasa.org/content.aspx?id=4220

Webster County District Website. 4 Day School Week. Retrieved June 2013, from http://www.webster.k12.ky.us/About/4DaySchoolWeek/tabid/58/Default.aspx

This work is licensed under a Creative Commons Attribution 3.0 License. 